CDD: 100

\title{
CONTEXTS, NON-SPECIFICITY, AND MINIMALISM
}

\section{EROS CORAZZA}

ILCLI, University of the Basque Country UPV/EHU,

Carlos Santameria Xentroa 2, Elhuyar Plaza, 20018, Donostia San-Sebastian, Spain

IKERBASQUE, Basque Foundation for Science, Bilbao, Spain

E Philosophy Department, Carleton University, Ottawa, Canada,

Paterson Hall 3a, 1225 Colonel By Drive Ottawa ON, K1S 5B6, Canada

eros_corazza@yahoo.com

\section{Received: 09.01.20I4; Revised: 05.05.20I4; Accepted: 07.05.2014}

\begin{abstract}
Atlas (2007) argues that semantic minimalism (as defended by Cappelen \& Lepore 2005) fails because it cannot deal with semantic non-specificity. I argue that there is a plausible version of minimalism-viz., situated minimalism-which doesn't succumb to the non-specificity charge insofar as non-specificity can be dealt with at a postsemantic level. Thus, pragmatics plays no role when it comes to determining the (minimal) proposition expressed. Instead, pragmatic and other extra-semantic considerations enter the scene in characterizing the situation vis-à-vis which the proposition is evaluated. For this reason a plausible form of minimalism must embrace a form of truth-relativism: a proposition is not universally true/false, but true/false only relative to a situation. I show how the position defended is not only (i) more cognitively plausible than either (semantic) minimalism as proposed by Cappelen \& Lepore or the positions appealing to pragmatic intrusion into the proposition expressed, but is also (ii) in accordance with ordinary people's intuitions.
\end{abstract}

Keywords: Contexts, evaluation, minimalism, non-specificity, pluri-propositionalism

Manuscrito - Rev. Int. Fil., Campinas, v. 37 , n. 1, p. 5 - 50, jan.-jun. 2014. 


\section{NON-SPECIFICITY AND MINIMALISM}

It is commonly held that a sentence of the form

(1) The A is not B

has two readings: narrow scope/predicate negation reading vs. wide scope/sentence negation reading. In other words, (1) can be read as either:

(1) a. The $\mathrm{A}$ is not $\mathrm{B}$ [narrow scope]

(1) b. It is not the case that the A is B [wide scope]

Atlas (2007) suggests that the minimalist account proposed by Cappelen \& Lepore (2005) cannot deal with the narrow/wide scope reading of an utterance of (1). His main charge boils down to the fact that within Cappelen \& Lepore's minimalist framework the truth-conditions of (1) are represented as follows:

(2) a. Any utterance of "The $\mathrm{A}$ is not $\mathrm{B}$ " is true iff the $A$ is not $B$

The problem is that (2a) fails to capture the two readings of (1)-i.e. (1a) and (1b). It is, therefore, not true that any utterance of (1) is true iff the A is not B. Again, this is due to the fact that an utterance of (1) may express the sentence negation (wide scope) or the predicate negation (narrow scope). ${ }^{1}$ Furthermore, since Cappelen \& Lepore are committed to the claim that any utterance of (1) expresses the very same (minimal) proposition, i.e. that the $A$

\footnotetext{
${ }^{1}$ Arguments against the Davidsonian truth-conditional framework adopted by Cappelen $\&$ Lepore have been previously proposed by Atlas (1977).

Manuscrito - Rev. Int. Fil., Campinas, v. 37 , n. 1, p. 5 - 50, jan.-jun. 2014.
} 
is not $B$, their position is flawed. For, given the two readings of (1), there cannot be a unique proposition expressed: there is more than one proposition that can be expressed through an utterance of (1) (see Atlas 2007: 224).

An easy and obvious way out of this charge is to take a Russellian strategy and argue that (1) is structurally ambiguous, and its meaning depends on whether you interpret the 'not' in (1) as taking a narrow or wide scope. In other words, whereas (1a) has the structure:

(1) c.

$$
\exists x[(\mathrm{Ax} \& \forall y(\mathrm{Ay} \rightarrow \mathrm{x}=\mathrm{y})) \& \neg(\mathrm{Bx})]
$$

(1b), instead, has the following structure:

(1) d. $\neg \exists x[(\mathrm{Ax} \& \forall y(\mathrm{Ay} \rightarrow \mathrm{x}=\mathrm{y})) \& \mathrm{Bx}]$.

If (1) is in fact structurally ambiguous Atlas' argument collapses, because, as Cappelen \& Lepore point out, before determining a sentence's truth-conditions a process of disambiguation must occur. ${ }^{2}$ Atlas, though, pre-empts this move. He claims that a sentence of the form "The A is not B" is not ambiguous:

I held that there was a context-free literal meaning, and that, in a sense of 'determine' best understood as 'constrain', it determined whether an utterance of the sentence in that context is literally true or false. For me ... 'The king of France is not bald' was an unambiguous sentence, one without ambiguity of scope, or

${ }^{2}$ Cappelen \& Lepore explicitly claim that one of the steps that needs to be taken in order to fix the proposition semantically expressed by an utterance of sentence $S$ is to "disambiguate every ambiguous/polysemous expression in S” (2005: 145).

Manuscrito - Rev. Int. Fil., Campinas, v. 37 , n. 1, p. 5 - 50, jan.jun. 2014. 
homonymy of lexical items, for 'not'. In one context an utterance of the sentence would literally express the narrow-scope, predicate negation proposition (or truth-conditions), and in other contexts it would literally express the wide-scope, sentence negation proposition (or truth-conditions). (Atlas 2007: 218)

Instead of positing an ambiguity Atlas suggests that a sentence like (1) is semantically non-specific. That is, the sentencetype "The $\mathrm{A}$ is not $\mathrm{B}$ " is neutral vis-à-vis the two readings:

In neither case is the utterance true if and only if the A is not B, where the alleged 'truth-condition' on the right-hand side of the biconditional is expressed by a semantically non-specific sentence of the meta-language. (Atlas 2007: 223)

The approach I take for the rest of this paper is as follows. First, I assume that Atlas is right and that a sentence like (1) is not ambiguous. In other words, I assume that (1) is a semantically non-specific sentence. ${ }^{3}$ Second, I propose a form of minimalism that can accommodate the non-specificity of (1) without having to embrace some form of pragmatic intrusion, or free enrichment, into what is said or expressed by the utterance of a sentence like (1)-in other words, this form of minimalism allows what is said to remain non-specific. Finally, I argue that the position I propose can accommodate a form of cognitive parsimony and, as such, may be more psychologically plausible

\footnotetext{
${ }^{3}$ Non-specificity shouldn't be confused with incompleteness. While the former is a logico-linguistic analysis, incompleteness is not: the latter "trades entirely on intuitions about 'conceptual content', 'propositions', 'what is said', 'what is said literally', 'what is said strictly speaking', et al" (Atlas 2007: 228). For a defense of semantic non-specificity see also Bach: "To regard sentences as semantically non-specific is to recognize the possibility that the semantic representation or logical form (if we allow nonclassical logical forms) of a sentence does not completely specify a proposition" (Bach 1982: 598).

Manuscrito - Rev. Int. Fil., Campinas, v. 37 , n. 1, p. 5 - 50, jan.-jun. 2014.
} 
than other forms of minimalism or proposals that appeal to free pragmatic enrichment in characterizing the semantic content of a declarative utterance.

\section{RESCUING MINIMALISM}

In order to avoid Atlas' criticism against minimalism as it is formulated in the previous section, I start by distinguishing between various ways context can be exploited both in a linguistic interchange and in cashing out an utterance's truth-conditions. To begin with we can distinguish between presemantic, semantic, and postsemantic (or “content supplementing”, to borrow Perry's recent characterization) use of context. ${ }^{4}$

At the presemantic level, context is used to figure out the meaning of words, to disambiguate, to determine which homonym

\footnotetext{
${ }^{4}$ As Perry puts it: "Sometimes we use context to figure out with which meaning a word is being used, or which of several words that look or sound alike is being used, or even which language is being spoken. These are presemantic uses of context: context helps us to figure out meaning. In the case of indexicals, however, context is used semantically. It remains relevant after the language, words and meanings are all known; the meanings direct us to certain aspects of context. Both these uses of context differ from a third. In the third type of case we lack the materials we need for a proposition expressed by a statement, even though we have identified the words and their meanings, and have consulted the contextual factors the indexical meanings direct us to. Some of the constituents of the proposition expressed are unarticulated, and we consult the context to figure out what they are. I call these 'contentsupplementing' uses of context. Finally and importantly we use context to interpret the intention with which the utterance was made, what was the speaker trying to do? This is the pragmatic use of context" (Perry 2001/2012: 47-8).
}

Manuscrito - Rev. Int. Fil., Campinas, v. 37 , n. 1, p. 5 - 50, jan.jun. 2014. 
is used, to resolve polysemy, to decide which language is used, etc. If, for instance, one hears or reads "David went to the bank" one needs to know who among the many Davids (David Kaplan, David Smith, David Israel, David Matheson, David Beckham, David Silva, etc.) went to the bank and whether he went to the financial institution or to the riverside. If one comes across "John saw Jane with the binoculars" one must determine, before processing its truth-conditions, whether it is of the form "s[John vP[saw NP[Jane with binoculars]]]" or of the form "s[John vP[saw NP[Jane] PP[with binoculars]]]". If one hears 'Ich!, one ought to know whether it is an utterance made by an English speaking person and thus expressing some kind of disgust or pain, or an utterance produced by a German speaker meaning 'I'. These choices take place at the presemantic level. Consider the English homonym 'bank', for which we happen to have two completely different definitions. That is, there are basically two words referred to as 'bank'. In other languages, however, there is no such problem with 'bank'. In order to translate 'bank' into French, for example, we would first have to disambiguate the word and decide whether to use 'banque' or 'rive'.

At the semantic level, context is exploited in order to determine the referent of so-called indexical expressions ('I', 'here', 'now', 'today', and the like). That is, after all expressions are disambiguated-both structural ambiguity and polysemy are resolved, the language fixed, etc.-context nonetheless remains relevant, given that the content or referent of indexical expressions can be determined only relative to the context of the utterance itself. As Kaplan (1977) forcefully pointed out, indexicals have a linguistic meaning (character) which can be represented as a function that takes context as its argument (where the parameters of context are agent, time, location, demonstratum, and possible 
world) and outputs the referent (content) as value. The linguistic meaning of 'today', for instance, can be characterized as "the day in which this token is uttered" which takes as argument the relevant day and gives as value that very day. We cannot fix the referent of an indexical expression at the presemantic level: we don't have infinitely many 'I's or 'now's standing for infinitely many individuals or times. A language like that would be, if not impossible, radically different from natural languages such as English, Spanish, Russian, Navajo, etc. Furthermore, 'I' and 'now' are not ambiguous terms. They are not proper names either. They are particular words working in a specific way. In English we have just one 'I' and one 'now' that we all use to refer to different people and moments depending on the context in which we happen to be. This seems to be a universal phenomenon across natural languages. If we translate ' $\mathrm{I}$ ' into French we have 'je' which presents the very same semantic profile.

At the postsemantic level context is relevant in cashing out an utterance's truth value. If one were to hear

(3) It's raining

one ought to determine where it is raining. For, rain occurs at times and locations. Yet, in "It's raining" no location is picked out by an element of the utterance (unlike in "It's raining here" or "It's raining in London" where the relevant place is referred to by 'here' and 'London').

There seem to be at least three ways one can represent the truth-conditions of an utterance of (3):

(3) a. An utterance $u$ of "It's raining" is true iff it's raining

Manuscrito - Rev. Int. Fil., Campinas, v. 37 , n. 1, p. 5 - 50, jan.-jun. 2014. 
(3) b. An utterance $u$ of "It's raining" is true iff it's raining in $l$

(3) c. An utterance $u$ of "It's raining" is true iff it's raining in the situation (location) of $u$

(3a) captures the minimalist approach proposed by Cappelen $\&$ Lepore. (3b) captures Perry's (1986) view according to which the relevant location is an unarticulated constituent of the proposition expressed; that is, the location enters the proposition expressed without being specified by any linguistic element either at the surface or at the deep (logical form) level. ${ }^{5}$ (3c), on the other hand, captures the view according to which the proposition expressed can be minimal-that is, without the relevant location being a (unarticulated) constituent of the proposition expressed. Nonetheless, the truth value of the proposition depends on the situation (location) vis-à-vis which the proposition is evaluated. ${ }^{6}$

${ }^{5}$ Linguists and philosophers keen on Relevance Theory (e.g.: Sperber \& Wilson 1986/1995, Bezuidenhout 2002, Carston 2002) would also endorse a position similar to Perry's, for they accept pragmatic intrusion into semantics. This also captures the position defended by so-called indexicalists (e.g. Stanley 2001) that posit a hidden argument (or indexical) in the logical form of "It's raining". In that case the location is articulated. In this paper I will not discuss this position given that, as interesting as it may be, it transcends the scope of the present essay.

${ }^{6}$ Following Barwise \& Perry's (1983) a situation can be characterized as a partial possible world: "Reality consists of situations-individuals having properties and standing in relation at various spatiotemporal locations. We are always in situations; we see them, cause them to come about, and have attitudes toward them" (Barwise \& Perry 1983: 7). A real situation comprises infinitely many aspects. Yet we can cognize only parts of it. What we end up cognizing depends on many factors such as our interests, activities, practices, etc. The very same individuals and properties may appear in different situations. As such they are uniformities. Locations and time are uniformities as well insofar as different things can happen in Manuscrito - Rev. Int. Fil., Campinas, v. 37 , n. 1, p. 5 - 50, jan.jun. 2014. 
The truth value of the minimal proposition that it is raining is thus relative to a situation: the very same (minimal) proposition can be true vis-à-vis one situation and false vis-à-vis another situation. This latter position can be characterized as a form of relativized minimalism, inasmuch as a proposition is not, pace the Fregean tradition, true/false absolutely, but is instead only true/false vis-àvis the situation in which it is evaluated. The very same (minimal) proposition can be true in one situation while false in another situation. $^{7}$

Furthermore, this position captures the intuition that two speakers may be classified as same-sayers even if they utter (3) in different locations: despite the fact that John utters (3) in New York and Jane utters it in Rome, it remains nonetheless correct to say that John and Jane said the same thing. Note that this is so even if what John says is true (because it is raining in New York) and what Jane says is false (because it is not raining in Rome).A word of clarification may be in order. As Lewis (1980) pointed out, the notion of what is said is not univocal; it can mean various things. To begin with, two persons can be classified as saying the same thing inasmuch as they express the same proposition (or Kaplanian content). Thus if John were to utter "I'm rich", Jane can say the same thing in uttering "You [addressing John] are rich". Jane could also say the same thing (i.e. express the same proposition) by saying "John is rich". In such a case, to express the same proposition, John and Jane must utter different sentences.

the same location at different times and various things can be going on at the same time in different locations.

${ }^{7}$ Alternative versions of truth-relativism have also been proposed by MacFarlane (2003, 2005, 2007) and Predelli (2005), among others. For a discussion of the various positions on the market and how they differ from contextualism see Davis (2013).

Manuscrito - Rev. Int. Fil., Campinas, v. 37 , n. 1, p. 5 - 50, jan.-jun. 2014. 
But John and Jane could be classified as same-sayers even if they express different propositions. If, for instance, John utters, "I admire you [addressing Jane]" Jane could reply: "I admire you [addressing John] as well"-or simply "Me too". In such a case Jane and John utter the same sentence and express different propositions. In short, two persons can be classified as saying the same thing either when they utter the same (or a very similar) sentence, or when they express the same proposition. This can be further highlighted if we consider:

A. John said that he (himself) is rich

Jane said that too

This can be interpreted in two ways-that is, as Jane saying that John is rich (strict identity reading) or as Jane saying that she (herself) is rich (sloppy identity reading). This suggests that 'saying' in some cases can be ambiguous, for it has either a de re or de dicto (or de se) reading. ${ }^{8} \mathrm{~A}$ very similar, story can be told about John (in New York) and Jane (in Rome). If they both utter (3)[It's raining], they can be classified as either (i) saying the same thing insofar as they utter the same string of words or(ii) saying different things, for what they say occurs in different situations. ${ }^{9}$ It is worth

\footnotetext{
${ }^{8}$ In considering similar examples, Lewis claims: "In every case, the proper naïve response is that in some sense what is said is the same for both sentence-context pairs, whereas in another-equally legitimate-sense, what is said is not the same ... It can mean the propositional content ... It can mean the exact words" (Lewis 1980: 41). For a detailed discussion of the notion of what is said and the problem it faces when dealing with 'I'thought and de se assertions in general see Stojanovic (2011). For a detailed discussion of the notion of same-saying see Corazza (2012).

${ }^{9}$ This debate could further be framed in terms of Austinian propositions (cf. Barwise \& Etchemendy 1987). John and Jane could be classified as Manuscrito - Rev. Int. Fil., Campinas, v. 37 , n. 1, p. 5 - 50, jan.-jun. 2014.
} 
noticing, though, that two people can be classified as same-sayers when uttering the same string of words, and yet expressing different propositions, only when indexical reference (in particular when a de se attitude) is involved. If, for instance, both John and Jane utter "David Kaplan is American" with John having in mind David Kaplan the UCLA logician, while Jane intends David Kaplan the film-maker, they cannot be classified as saying the same thing. For, as I suggested, whether one uses the name 'David Kaplan' to refer to the logician, the film-maker, or one of the many others sharing the name 'David Kaplan', is a question that must be resolved at the presemantic use of context. This parallels two people uttering "Sue went to the bank", with one intending that Sue went to the river-bank and the other intending that she went to the financial institution. Like ambiguity, cases of homonymy should be resolved at the presemantic use of context. One commits oneself to the view that in such cases two people could be classified as same-sayers if one assumes that cases of ambiguity and homonymy must be treated like indexical reference and, as such that 'David Kaplan' and 'bank' would exploit a semantic use of context, just like words such as 'I', 'now' and 'tomorrow' do.

To further highlight how the notion of same-saying is important when putting forward a theory of communication, it may be useful to consider the role same-saying plays in the following arguments:

same-sayers inasmuch as they express the same (minimal) proposition, namely that it is raining. Yet they wouldn't be classified as same-sayers if we consider the full truth-conditional content to be an Austinian proposition: i.e. a proposition that includes the situation under which the utterance took place, insofar as John and Jane's utterances are sensitive to different situations.

Manuscrito - Rev. Int. Fil., Campinas, v. 37 , n. 1, p. 5 - 50, jan.jun. 2014. 
B. John said that Sue is happy

Jane said all that John said

So: Jane said that Sue is happy

C. John said that Sue is ready

Jane said all that John said

So: Jane said that Sue is ready

These two arguments are prima facie valid and a plausible theory of communication should account for their validity. The natural answer that comes to mind is that Jane and John are samesayers inasmuch as they express the same proposition. Notice, however, that if what John said is expanded or enriched, then for Jane to say the same thing as John, the proposition she expressed must be enriched or expanded in the very same way. If in uttering "Sue is ready" John were expressing the proposition that Sue is ready for the exam, whereas Jane's utterance of the same words was instead meant to express the proposition that Sue is ready for the party, then (C) would no longer be valid. Despite uttering the same sentence, John and Jane are not saying the same thing-i.e., they wouldn't express the same proposition. ${ }^{10}$ In the interpretation

\footnotetext{
${ }^{10}$ For a detailed discussion regarding the importance of the notion of same-saying in a theory of communication see Corazza (2012). A contextualist tenet appealing to free enrichment could argue that if we fix the (broad) context the argument turns out to be valid, for John and Jane would enrich the minimal proposition (propositional template or logical form) in the same way. This move, though, seems to give up the contextualist intuition that the proposition expressed (what is said) is the Manuscrito - Rev. Int. Fil., Campinas, v. 37 , n. 1, p. 5 - 50, jan.-jun. 2014.
} 
I proposed, the argument is valid. For: (i) if saying the same thing amounts to expressing the same proposition, it suffices to fix the situation vis-à-vis which the proposition is evaluated for the argument to be valid and (ii) if saying the same thing amounts to uttering the same sentence, the argument is also valid for John and Jane both uttered "Sue is ready".

The notion of situation encapsulates the intuitive idea that our discourses and linguistic interchanges, not to mention our cognitive activity, concern given situations. If one utters "Messi scored two important goals" while watching the BarcelonaManchester United champions league match, what one says is true if and only if Messi scored two important goals during that match. The important goals Messi scored the previous week when playing for Argentina don't make the relevant utterance true. In short, our utterance concerns the Barcelona-Manchester United game the speaker is watching; it does not concern any other game. One's utterances (and one's accompanying thoughts) are, one could say, situated. ${ }^{11}$ This view is consonant with the minimalist program, for

one a competent speaker processes or comes to grasp, i.e. the proposition the speaker means. It is worth mentioning that the adherents of Relevance Theory deny that the notion of same-saying plays an important theoretical role when explaining communication: "We ourselves do not claim that all utterances have a literal meaning, and we will be arguing that even when a literal meaning is available, it is not automatically the preferred interpretation of the utterance. In fact, literalness plays no role in our account of language comprehension, and nor does the notion of what is said" (Wilson \& Sperber 2002: 586). If literal meaning plays no role, it is then difficult, if not impossible, to classify speakers as same-sayers.

11 "In situation theory, we take note of the fact that an agent's world divides up into a collection, or a succession, of situations; situations encountered, situations referred to, situations about which information is Manuscrito - Rev. Int. Fil., Campinas, v. 37 , n. 1, p. 5 - 50, jan.jun. 2014. 
alleged unarticulated constituents don't enter the proposition expressed. ${ }^{12}$ They do, however, play a role when it comes to determining the utterance's truth value. But they can do so by remaining in the situation relative to which the proposition is evaluated without making their way into the proposition expressed.

The important point to stress is that according to the views represented by (3b) and (3c), the relevant location enters the scene at the postsemantic level. It cannot be determined at the presemantic level. In "It's raining" the verb 'to rain' is not ambiguous. Nor is it a case of polysemy, vagueness, or even of non-literal use. Furthermore, 'to rain' isn't an indexical having a Kaplanian character that takes as input some contextual parameters and gives out as value the relevant location. If it were so, most verbs would work, contrary to our commonsensical intuitions, on the model of indexicality. Take 'to dance' and 'to eat', for instance: it is a metaphysical fact that one always dances and eats in a place.

received, and so on. That is to say, our theory reflects the fact that agents through their behavior discriminate situations: the behavior of people varies systematically according to the kind of situation they are faced with: threatening situations, spooky situations, pleasant situations, challenging situations, conversations, and what-have-you, all evoke quite different responses" (Devlin 1991: 30).

${ }^{12}$ The position I am defending is thus consonant with what Cappelen \& Lepore consider the basic idea underlying minimalism: "The idea motivating Semantic Minimalism is simple and obvious: The semantic content of a sentence $S$ is the content that all utterances of $S$ share. It is the content that all utterances of $S$ express no matter how different their contexts of utterance are. It is also the content that can be grasped and reported by someone who is ignorant about the relevant characteristic of the context in which an utterance of $S$ took place" (Cappelen \& Lepore 2005: 143).

Manuscrito - Rev. Int. Fil., Campinas, v. 37 , n. 1, p. 5 - 50, jan.-jun. 2014. 
Yet it wouldn't make much sense to claim that the location makes its way into the proposition expressed by utterances of sentences like:

(4) Sue danced all night.

(5) Jane ate lots of cookies.

There is always a location where events like eating and dancing occur: as a matter of fact one cannot dance and eat outside of space. Whether Sue danced at the Velvet Club or at Ivan's party doesn't seem to matter when we compute what one says in uttering (4) or (5). With meteorological terms the story seems to be a bit different: for example, if it is raining in New York and we're in sunny Rome we don't take an umbrella when going out. The location can thus affect our behavioral dispositions. However, the location where one dances or eats may also affect someone's behavior. If one eats at one's local pub or at the White House with President Obama one's behavior is likely to differ as well (e.g.: one would dress formally to eat with Obama but informally to eat at her local pub). Given that a location does not make its way into the propositions expressed by utterances of (4) and (5), it seems somewhat arbitrary that a location should make its way into the proposition expressed by uttering sentences like (3). As far as I can see, this isn't a question that needs to be addressed by semantics; it pertains to metaphysics. We could nonetheless claim that since we're embodied in a world and time, we don't usually need to represent them (when engaged in modal logic or questions of

Manuscrito - Rev. Int. Fil., Campinas, v. 37 , n. 1, p. 5 - 50, jan.jun. 2014. 
identity across possible worlds, we may represent the actual world). ${ }^{13}$

Instead, I suggest an alternative way to represent the truthconditions of utterances such as (3), (4), and (5) that seems not to leave any important facts out of the picture and still captures ordinary speakers' intuitions. In accordance with common use, this framework considers the utterance "It's raining" true if uttered in New York (on a rainy day), while false if uttered in Rome (on a sunny day). However, it is true/false because what is (literally) said occurs in different places: it is not true/false because the different locations (New York and Rome) enter the proposition expressed. Both in New York and in Rome, in uttering "It's raining" one says the same thing, one expresses the same (minimal) proposition. ${ }^{14}$ Yet, what one says is true/false because it is said in different locations: i.e. because the (minimal) proposition is evaluated in different situations (locations). If so, the relevant location need not enter at the semantic level. ${ }^{15}$ It can be determined at the postsemantic level. A similar story can be told about utterances of (4) and (5). The truth-conditions of (4), for instance, could be spelled out as follows:

\footnotetext{
${ }^{13}$ If one adopts Kaplan's framework, the time as well need not enter the proposition expressed; it pertains to the context of evaluation (or the situation vis-à-vis which the timeless proposition is evaluated). ${ }^{14}$ As I've already mentioned, an obvious advantage of the position I am advocating is that it can easily and intuitively deal with the notion of same-saying. For a long discussion of same-saying across different contexts see Cappelen \& Lepore (2005). See also Corazza (2012). ${ }^{15}$ Once again, I am ignoring the position advocated by so-called indexicalists (e.g. Stanley 2000) who claim that 'to rain' presents an argument place (a hidden indexical) for a location at the level of logical form.
}

Manuscrito - Rev. Int. Fil., Campinas, v. 37 , n. 1, p. 5 - 50, jan.jun. 2014. 
(4) a. An utterance $u$ of "Sue danced all night" is true iff Sue danced all night in the situation of $u$

With a change in situation we could have different truth values. If John, at the Velvet Club at 4:30 am, pointing toward someone he mistakenly takes to be Sue, utters (4), John says something false. Sue is not at the Velvet Club and, as such, she did not dance all night in that relevant situation. In that case John says something false even if it so happens that Sue danced all night in another situation (e.g. at Ivan's party). ${ }^{16}$ Hence, I do not think that there is a substantial difference between (4) and (5), on one hand, and an utterance of (3), on the other hand. In particular, I do not think that there is a difference that deserves to be reflected in the proposition expressed. Representations like (3c) and (4a) fit with our intuitions.

Furthermore, the framework I am proposing, inspired by Perry (2001/2012) and Korta \& Perry (2011), can be characterized as being "pluri-propositional". As such, it contrasts with monopropositionalism: viz. the view that the utterance of an

\footnotetext{
${ }^{16}$ This echoes Barwise \& Etchemendy's (1987: 121-2) classical and appealing example concerning Claire and the poker game. Looking at the game, Jon says: "Claire has the three of clubs". Jon's utterance expresses the proposition that Claire has the three of clubs. This utterance concerns the situation of the game of poker watched by Jon. For Jon's utterance to be true, it is not sufficient that the proposition or fact it expresses obtains. This proposition must obtain in the relevant situation: i.e. the poker game being watched by Jon. If Jon is mistaken in identifying Claire, and Claire is not among the players of the poker game, Jon's utterance cannot be true. Furthermore, his utterance would not be true even if Claire were playing poker in another part of town and happened to have the three of clubs. Jon's utterance is true only if Claire has the three of clubs in that poker game-that is, in the game being watched by Jon.
}

Manuscrito - Rev. Int. Fil., Campinas, v. 37 , n. 1, p. 5 - 50, jan.-jun. 2014. 
unambiguous sentence is associated with a single proposition. This doesn't mean, however, that for each utterance there is necessarily more than one proposition expressed. ${ }^{17}$ It simply means that every utterance is systematically associated with a family of contents that derive from the combination of the speaker's intentions and beliefs, the exploited linguistic conventions, and the circumstances of the utterance. The truth-conditions of these contents can be classified by different propositions: some of these propositions are reflexive or utterance-bound propositions, with the utterance itself as a constituent. These variegated contents expand from the purely reflexive to the official content: they constitute a family of gradually less reflexive and more incremental propositions.

To highlight this, let's suppose that Jane utters (6) while John utters (7):

(6) I love to dance

(7) Jane loves to dance

\footnotetext{
${ }^{17}$ The pluri-propositionalism I'm discussing here differs from the view advocated by some philosophers (e.g.: Bach 1999, Neale 1999, and Dever 2001; see also Corazza 2002, 2002a, 2003, 2005) who claim that some utterances may express more than one proposition-in the terminology introduced here they would be associated with more than one official content. As such, pluri-propositionalism is neutral on whether some utterances can express more than a proposition. When Perry (1988) first introduced this framework he distinguished between propositions expressed (the official/incremental content) and propositions created (the reflexive truth-conditions). For a more detailed discussion of Perry's (2001/2012) and Korta \& Perry's (2011) pluri-propositionalist framework, see Corazza (2011, 2012) and Corazza \& Korta (2010).
}

Manuscrito - Rev. Int. Fil., Campinas, v. 37 , n. 1, p. 5 - 50, jan.-jun. 2014. 
The proposition expressed, the official (or Kaplanian) content, by (6) and (7) is the following:

(6/7) a. That Jane loves to dance

(6) and (7) express the very same singular proposition with Jane as a constituent. Their official content is the same. This, though, doesn't help in explaining, for example, why Jane would utter (6) but not (7) if she desires John to invite her to dance. John may even be unaware that the person talking to him is named 'Jane'. Even if John knew that the name of the person in front of him is 'Jane' it would be nonetheless awkward for Jane to utter (7).

The reflexive content of an utterance like (6) corresponds to what a competent hearer would understand. This understanding rests on her mastery of English and no other contextual information besides the fact that (6) has been produced. This can be rendered by the following proposition:

(6) b. That the speaker of (6) loves to dance

(6b) is a reflexive proposition for it has (6), the utterance itself, as a constituent. It is, therefore, a singular proposition having an utterance as a constituent. ${ }^{18}$ This, though, is not the proposition expressed. It is not what Jane said in uttering (6). Yet the

\footnotetext{
${ }^{18}$ Reflexive propositions, like any proposition, are abstract entities. They are good tools we can use to classify both the content of an utterance and someone's mental state: that is, the mental state one is in when one expresses or grasps the official content. If one is keen on the language of thought hypothesis we could say that reflexive propositions help to classify sentences in Mentalese. Only the latter have causal power. Reflexive propositions qua abstract entities don't have causal power.
} Manuscrito - Rev. Int. Fil., Campinas, v. 37 , n. 1, p. 5 - 50, jan.jun. 2014. 
realization of Jane's plan depends on its being understood: it is only because John understands (6b) and notices that the speaker of (6) is the person sitting next to him, that he can grasp the following:

(6) c. That the person in front of me loves to dance ${ }^{19}$

Once again, this is not the proposition expressed by (6). It is not what Jane said. It is nevertheless the relevant content that John should grasp for Jane's plan to succeed. In other words, it is the content that helps John to be in a position to invite Jane to dance. It is this content which accounts for the cognitive motivation and cognitive impact of (6). (6c) is understood on the basis of the hearer's knowledge of English (i.e. (6b)) and his perceptual awareness of the context of the utterance-who the speaker is and where she is located. The last section of this paper explains how in coupling this framework with situated minimalism we can deal with the utterance of a non-specific sentence without giving up Atlas's insight that a non-specific sentence has a context-free literal meaning.

Before going any further, I am now going to argue that, on top of capturing our intuition, the minimalist position proposed so far is cognitively plausible for it reflects what we could characterize as a form of cognitive parsimony.

\footnotetext{
${ }^{19}$ This reflexive proposition helps to classify the mental state one would express in saying "She/that person loves to dance": namely, a mental state one would demonstratively anchor to the speaker of (7). In our example it is this token mental state that triggers John's action.
}

Manuscrito - Rev. Int. Fil., Campinas, v. 37 , n. 1, p. 5 - 50, jan.-jun. 2014. 


\section{MINIMALISM FROM A COGNITIVE PERSPECTIVE}

One of the main insights from Perry (1986) is that we can have thoughts without representations. In other words, a thought can concern something without having to represent that very thing. Think, for instance, of the thought a little child would entertain in uttering "It's 2:00 pm". This thought concerns a relevant time zone without the speaker having to represent it. ${ }^{20} \mathrm{~A}$ child who is unaware of time zones can utter "It's 2:00 pm" and, in so doing, succeed in passing along some relevant information and engage in a successful linguistic exchange. Our child's speech act can be successful even if the speaker (and the hearer) do not represent the relevant time zone-e.g. without them having to think that it is, say, 2:00 pm Pacific Time. Little-John and little-Jane can decide to meet for a play-date at 2:00 pm without their having to represent the relevant time zone. They can even lack the cognitive resources to represent time zones. In cases like this, the situation in which the linguistic exchange occurs may well furnish the alleged missing ingredients (e.g. the time zone) without the speaker and/or the audience having to articulate them in their utterance and their corresponding thoughts.

${ }^{20}$ The terminology may be a bit misleading insofar as I distinguish between concerning and aboutness. To have a thought about something, one needs to form a mental representation of this very thing (e.g.: one should have a mental token of that thing in his/her language of thought). On the other hand, a thought can concern something insofar as it is situated and the thinker need not entertain a mental representation (e.g.: a token in his/her language of thought) of this very thing. It is in this sense that the thought one would express by "It's raining"/“It's 2:00 pm" can concern a given location/time zone, without the speaker entertaining a mental representation of the location/time zone in his/her mind. Manuscrito - Rev. Int. Fil., Campinas, v. 37 , n. 1, p. 5 - 50, jan.-jun. 2014. 
The same happens in many of our everyday interchanges. When Jérôme, at the Montparnasse train station in Paris, is asked about the time, he automatically consults his wrist-watch and replies: "It's 3:15". In so doing he reliably tells the time to his audience. Yet he doesn't say that it is $3: 15 \mathrm{pm}$, let alone that it is 3:15 pm Central European Time. The simple fact that Jérôme is in Paris (and that Paris' time is CET) and that it isn't the middle of the night suffices for him to reliably convey the appropriate message. To do so, Jérôme need not articulate, either in his utterance or in his thought, that the time in question is $\mathrm{pm}$ and CET. It is in this sense that I said that the situation provides the relevant parameters (in our example, CET and the afternoon) that underlie the success of the communication.

If Jérôme's watch were set to another time zone, the situation (CET and the afternoon) wouldn't grant the success of the communication, given that Jérome would fail to pass on the right information to his audience and, as a consequence, the latter might miss their train. Were Jérôme and his partner's wristwatches set to Western Samoa time (twelve hours ahead of CET), for example, in uttering "It's $3: 15 \mathrm{pm}$ " as they get off the plane Jérôme could well convey that it is 3:15 am WST. However, in such a case the thought he aims to convey could be attuned either to CET or WST. In such a situation-in order to avoid confusionJérôme would likely have to specify the time zone and, in so doing, make explicit his intentions.

Most of the time, though, we don't have to bring to the surface our intentions (they may be simply operating at the subconscious level). If, looking out of the window, I say to my partner who is still in bed "It's storming", we automatically give up our plan to go out for a picnic. If, being in sunny Rome, I meant that it 
is storming in London because I just talked on the telephone with a friend over there, I would have to cancel the default interpretation that it is storming where we are and add that it is storming in London. ${ }^{21}$

Since it is part of our background knowledge that we operate within time zones and that raining or storming occur in determinate places, we do sometimes have to mention them. That said, most of the time, in normal face-to-face communication we don't have to call to our minds representations of time zones or the location we are in when telling the time, or locations when reporting weather conditions. In other words, it is often the case

${ }^{21}$ In so doing the speaker (and his/her audience) would form a mental representation of the relevant location. If one were to hold the view, though, that one could have subconscious representations of, say, a time zone or location, one would reject Perry's insight that we can have thoughts concerning something without having to represent that very thing. No doubt, more should be said about the notion of representation. For my argument to hold, it suffices to say that for someone to represent something one must have a concept of that very thing. The question would thus reduce to: what does it mean to possess a concept? If one holds the view that in order to possess a concept one must be able to express it with a natural language expression(s), then infants unaware of time zones cannot possess the concept of, say, Pacific Time. Adults may possess this concept, for in a given situation they are disposed to express it. Yet, even if one possesses a concept, one may not actualize it in a specific thinking episode. One can have the concept of lemon even if one is not thinking or talking about fruits, let alone lemons. The same with time zones: one possesses the concept of time zones even when one is not thinking or talking about times. Furthermore, one may not call to one's mind the concept of time zones when one is thinking that it is $3: 15 \mathrm{pm}$. It is in this latter sense that we can say that someone may have a thought concerning something without having to represent that very thing, i.e. without calling to one's mind the concept of that very thing. Manuscrito - Rev. Int. Fil., Campinas, v. 37 , n. 1, p. 5 - 50, jan.jun. 2014. 
that the situations where our utterances (and accompanying thoughts) occur need not be made explicit and/or brought to the surface. This is, I reckon, a general economic cognitive principle superseding our linguistic interchanges and thinking activities.

Furthermore, we can say that Jérôme knows what time it is. Yet his knowledge rests on the presence of his wrist-watch. Had Jérôme forgotten his watch at home, his reply to "What time is it?" would likely be something like: "Sorry, I don't know. I don't have my watch with me". This parallels what happens when, asked about someone's phone number, one replies "I know but I don't remember, let me consult my iPhone", or when one claims to know someone's address or birthday because one has them stored in one's agenda. In these cases one's knowledge doesn't rely on information stored in one's mind as traditionally conceived: i.e., as a self-contained repository containing all of one's knowledge. We can say that some information pertains to one's mind as a situated entity. As such, it can involve "external" information: i.e., information that doesn't reside in one's skull and/or body.

Since in many cases the situation fixes all that needs to be fixed, the speaker and her audience need not represent what their discourse concerns. ${ }^{22}$ In a nutshell, what is fixed by a situation need

\footnotetext{
${ }^{22}$ See Perry (1996)'s Z-land story where the inhabitants of a little island, Z-land, never travel and don't have telephone communications and broadcasting information coming from the external world. When a Zlander utters "It's raining" her talk concerns Z-land (it rains in Z-land). Yet she doesn't (and need not) represent the location where it is raining. These islanders need not have representations for time zones either. The situation in which they utter, say, "It's 2:00 pm" provides all that is needed for them to get the time right and their actions are automatically attuned to it. Yet their time-utterances (and thoughts) concern a given time zone. These islanders, though, don't need any mental effort to Manuscrito - Rev. Int. Fil., Campinas, v. 37 , n. 1, p. 5 - 50, jan.-jun. 2014.
} 
not be fixed by the agent's representational system. This, as I have anticipated, reflects a principle of cognitive parsimony:

[E]volved creatures will neither store nor process information in costly ways when they can use the structure of the environment and their operations upon it as a convenient stand-in for the information-processing operations concerned. (Clark 1989: 64)

Just as relevant information can be stored in one's situation (or surroundings), other important information can be stored in one's long-term memory. As such, it need not be articulated in the agents' cognitive system. That is to say, it may be stored in their memory without their having to activate it when they engage in a communicative act. As I understand it, there is no principled difference between the information one stores in one's diary and the information one stores in one's long-term biological memory. All this information can be exploited by an agent's cognitive system without the latter having to articulate it-that is, without the agent having to bring it to the working memory. As Clark \& Chalmers (1989) suggest, there is no principled difference between information and beliefs stored in memory and information and beliefs stored in one's notebook. Someone may reliably believe that the meeting starts at $1: 00 \mathrm{pm}$ because they wrote it down in their notebook (see Clark \& Charmers' case of Otto who, suffering from Alzheimer's, cannot gather in his biological memory the relevant information and, as a consequence, reliably stores it and successfully retrieves it from his notebook).

As a further illustration we can consider some of our daily practices like driving or cycling to campus. Relevant information guiding our actions can be stored in our long-term memory so that

distinguish various time-zones. They are simply unaware of the existence of time zones.

Manuscrito - Rev. Int. Fil., Campinas, v. 37 , n. 1, p. 5 - 50, jan.-jun. 2014. 
we can automatically drive without having to articulate memories concerning our previous drives to campus-without having to think, for instance, whether we ought to turn right or left at the next stop. This is often the case when we engage in automatic, unreflective, actions. Furthermore, two or more persons can successfully engage in a joint automatic action because of some shared information stored in their long-term memories and/or surroundings. Further, they can successfully act without the relevant information having to reach their conscious minds. We can thus say that thoughts (e.g. the thoughts our agents would express in uttering "It's 3:15pm" or "It's raining") can trigger successful joint actions inasmuch as they concern some things (e.g. a time zone and a location) without these parameters having to be articulated or represented in the thoughts themselves. It is in this sense that we should understand the notion of a thought as being situated and the notion of people engaged in joint actions and their respective thoughts as being co-situated.

There is, therefore, a distinction worth making between context sensitivity and situation sensitivity. The utterance of a noneternal sentence is situation sensitive, for its truth value depends on the situation in which it is evaluated without the latter having to be represented by the speaker and/or hearer. The utterance of an indexical sentence, though, is context sensitive and the speaker and her audience need to represent the referent(s) contextually singled out or, to borrow Donnellan's terminology, they need to have the referent in mind..$^{23}$ If one is keen on the notion of the language of thought, we can say that interlocutors computing an indexical

\footnotetext{
${ }^{23}$ To be sure, the audience may not have the referent in mind (and thus entertain a singular thought) for the success of communication. A pragmatic implicature can be triggered by the reflexive truth-conditions (see Korta \& Perry 2006).

Manuscrito - Rev. Int. Fil., Campinas, v. 37 , n. 1, p. 5 - 50, jan.-jun. 2014.
} 
utterance entertain an indexical sentence in their mind. The indexical articulated elements anchor their thought to the relevant object which is (indexically) singled out. On the other hand, in computing an indexical-free, yet situation sensitive, utterance, two interlocutors need not entertain an indexical sentence in their mind. To illustrate that, we can consider, again, our JérômeMonteparnasse example. The simple facts that Jérôme utters "It's 3:15", his wrist-watch is set to CET, and the corresponding thought occurs in Paris, suffice. It is only in considering the mind (and/or brain) as self-contained that we fail to appreciate how information stored in one's surroundings and the situation one finds oneself in can play a crucial role in our linguistic thinking and interactions without having to be represented in our minds. No doubt, more should be said about the way information can be stored in memory and how it works in our thinking and linguistic interchanges without being actualized and/or articulated. ${ }^{24} \mathrm{As}$ Wilson\& Clark put it:

We are creatures embedded in informationally rich and complex environments. The computations that occur inside the head are an important but nonexhaustive part of the computational systems. (Wilson \& Clark 2009: 60)

Hence, it shouldn't be surprising that our thoughts are intrinsically and automatically connected (or situated) without our having to spend precious cognitive energy.

Recent studies in social cognition support this fact as well. Bargh \& Chartrand, for instance, convincingly argue that:

\footnotetext{
${ }^{24}$ For a detailed review article on this issue and on how shared memories work, see Sutton (2009).

Manuscrito - Rev. Int. Fil., Campinas, v. 37 , n. 1, p. 5 - 50, jan.-jun. 2014.
} 
$[\mathrm{M}]$ ost of a person's everyday life is determined not by their conscious intentions and deliberate choices but by mental processes that are put into motion by features of the environment and that operate outside of conscious awareness and guidance. (Bargh \& Chartrand 2005: 228-9)

Baumeister's (2005) notion of the duplex mind-viz., a conscious system and an automatic (unconscious) one collaborating in determining and guiding our actions-brings further evidence favoring the view that most of our actions and joint activities do not rest on conscious cognitive processing:

The human mind has two major processing systems at work, and they have different properties ... The automatic system, also known as the intuitive or reflexive system, generally has many things happening at once ... simultaneously and somewhat independently of each other. ... In contrast, the conscious system does one thing at a time, yet it can process in depth and follow multiple steps. ... only the conscious system seems fully able to make use of the power of meaning and language. (Baumeister 2005: 75)

Our mental processes can be automatically connected with the environment or situation we find ourselves in. The general moral is that self-contained computing plays a minimal causal role in the guidance of our everyday actions. It is because our thoughts are situated that linguistic interactions, in particular, and joint activities, in general, can be explained without having to posit representations for all the relevant items stored in the situation where the linguistic and thought episode occurs.

With these considerations in mind, I now turn to show how we can deal with Atlas' non-specificity challenge against minimalism. 


\section{NON-SPECIFICITY AND MINIMALISM}

To begin with, let's assume along with Atlas that a sentence of the form "The A is not B" is non-specific. My aim now is to show how minimalism can deal with the non-specificity phenomena applied to negation without having to posit that (1) is ambiguous. As I have already mentioned, the truth-conditions of an affirmative sentence can be cashed out according to the following T-schema:

(8) $S$ is true iff pins

Where ' $\mathrm{S}$ ' is the object language sentence, ' $\mathrm{p}$ ' the meta-language sentence translating ' $\mathrm{S}$ ', and ' $\mathrm{s}$ ' the situation vis-à-vis which $p$ must be evaluated. In quantifying over utterances we'll have:

(9) An utterance $u$ of $S$ is true iff pin the situation of $u$

If we adopt this schema to (alleged) non-specific sentences of the form "The $\mathrm{A}$ is not $\mathrm{B}$ " we have:

(10) An utterance $u$ of "the A is not $\mathrm{B}$ " is true iff the $A$ is not $B$ in the situation of $u^{25}$

The problem we now face is that the meta-language sentence the $A$ is not $B$ reproduces the non-specificity of the object language sentence "the A is not B". The problem seems to be that we cannot deal with the non-specificity of the natural language with respect to the scope of the negation at the semantic level. This is a

\footnotetext{
${ }^{25}$ In that case, the full truth-conditional content is what Barwise \& Etchemendy (1987) characterize as an Austinian proposition (i.e. a proposition that includes the situation concerned as well).

Manuscrito - Rev. Int. Fil., Campinas, v. 37 , n. 1, p. 5 - 50, jan.-jun. 2014.
} 
problem, though, only if one adopts, as Cappelen \& Lepore do, a non-relativized form of minimalism. That is to say, Atlas' argument is relevant only if one represents the truth-conditions of an utterance of "the $\mathrm{A}$ is not $\mathrm{B}$ " along the following T-schema:

(11) An utterance $u$ of "the A is not B" is true iff the $A$ is not $B$

But "the A is not B" cannot be said to be true (or false) without resolving the scope of 'not'. In terms of propositions, the nonspecific utterance "the $\mathrm{A}$ is not B" cannot express (without pragmatic intrusion into semantics) a proposition which is either true or false. If we have pragmatic intrusion, though, minimalism must be false.

If, as I suggested, one adopts a form of relativized minimalism one can avoid falling before Atlas' criticism, given that the non-specificity is resolved within the situation vis-à-vis which the non-specific proposition is evaluated. As such, we don't have to allow pragmatic intrusion into what is said-i.e. into the minimal proposition expressed. In other words, nothing prevents the proposition expressed from inheriting the non-specificity of the utterance expressing it. It is only when one adopts a form of truthabsolutism (i.e. the view that a proposition is true or false absolutely) that the non-specificity needs to be resolved at the semantic (or presemantic) level. Within the semantic minimalist framework I am proposing, non-specificity can be resolved at the postsemantic level.

A non-specific proposition is not, properly speaking, a proposition. In particular, it is not something that can be judged to be true/false without the use of further information. As such, a non-specific proposition comes close to being a propositional

Manuscrito - Rev. Int. Fil., Campinas, v. 37 , n. 1, p. 5 - 50, jan.-jun. 2014. 
matrix (cf. Bach 1994) in need of further information before it can be evaluated as being true/false. Unlike Bach's propositional matrices, though, the non-specific propositions I have in mind need not be expanded (or enriched). In other words, the alleged "missing ingredients" required for the enrichment or expansion of non-specific propositions (so that they can be evaluated as true/false) need not enter the proposition itself. They can remain in the situation vis-à-vis which the proposition is evaluated.

To stress this, let us consider, again, an utterance of "It's raining”. If one follows Bach, an utterance of it would express a propositional matrix that needs to be expanded (completed with a location): only the resulting product, the proposition expressed, would thus be true/false. In the picture I have in mind a proposition is never true/false (absolutely): it is only true/false vis$\grave{a}$-vis the situation in which it is evaluated. As a result the very same (minimal) proposition, or non-specific proposition, can be true in one situation while false in another. ${ }^{26}$ The proposition that it is raining may be true in London and false in Rome. The same with non-specific propositions: the non-specific proposition that the $\mathrm{A}$ is not $\mathrm{B}$ can be true in the situation where the negation takes wide scope and false in the situation in which 'not' takes narrow scope.

In short, minimalism faces problems with non-specificity in particular (and incompleteness in general) only when one confuses non-specificity with context-sensitivity or indexicality. As

\footnotetext{
${ }^{26}$ The proposition expressed by the utterance of an eternal sentence (e.g.: " $2+3=5$ ") would give the same result in each situation in which it is evaluated. Such propositions would be fully evaluable without recourse to situations given that they encompass all the relevant information necessary to compute their truth value.
}

Manuscrito - Rev. Int. Fil., Campinas, v. 37 , n. 1, p. 5 - 50, jan.jun. 2014. 
we saw, indexicality ought to be resolved at the semantic level. Non-specificity (like incompleteness) needs to be resolved at the postsemantic level. For this reason the utterance of a non-specific sentence need not express a truth-evaluable proposition. It can express a non-specific proposition that will be evaluated as true/false only relative to a situation.

Notice that by distinguishing between semantic and postsemantic use of context we can easily circumvent Atlas' criticism. We can accept that the sentence-type "The A is not $\mathrm{B}$ " is neutral vis-à-vis the two readings. Yet, pace Atlas, non-specific sentences do not undermine the minimalist program insofar as non-specificity (like alleged unarticulated constituents and other similar phenomena ${ }^{27}$ ) can be treated at the postsemantic level. In other words, just as utterances of sentences of "It's raining" can be accommodated into a minimalist framework without appealing to unarticulated constituents or pragmatic intrusion, the utterance of non-specific sentences like "the A is not B" can also be so treated.

Furthermore, if we adopt the pluri-propositionalist model I introduced in section 2,in considering the utterance of a nonspecific sentence we can discern between its referential (or official) content and its reflexive content. In so doing, we can highlight how the narrow/wide scope reading, for instance, can be determined in the situation where the non-specific proposition is evaluated.

${ }^{27}$ E.g.: comparative adjectives "Sue is strong" (strong as a teenage student or strong as an Olympic athlete?); quantifiers domains restrictions "Every bottle is empty" (every bottle in the fridge or every bottle in the shop?); possessive NPs, "John's book is interesting" (the book John owns or the book John wrote?), etc.

Manuscrito - Rev. Int. Fil., Campinas, v. 37 , n. 1, p. 5 - 50, jan.-jun. 2014. 
The reflexive content of an utterance of(1) [The A is not $\mathrm{B}] \mathrm{said}$ by Sue can be represented along the following line:

(12) In uttering "The A is not B" Sue says that the A is not B

(12) is what a competent speaker of English computes and can, without further information, faithfully attribute to Sue. The official content of (1) can be represented as:

(13) An utterance $u$ of "The $\mathrm{A}$ is not $\mathrm{B}$ " is true iff the $\mathrm{A}$ is not $\mathrm{B}$ in the situation of $u$

Thus if Sue utters (1) "intending" that it is not the case that the A is B (wide scope/sentence negation) and Jane utters it "intending" that the $\mathrm{A}$ is not B (narrow scope/predicate negation), we can say that Sue and Jane say the same thing and yet convey different messages. In that way, Sue and Jane can be classified as same-sayers. This parallels, to some extent, the situation when Sue and Jane both utter "I'm F". There is a level, classified by the reflexive content of the utterance, at which the two utterances are the same: i.e. "In uttering 'I am F' Sue/Jane said that she (herself) is F" (cf. Corazza 2004, 2012).

However, the official content is different: if the speaker is Sue, what she said-that is, the official content expressed-is that Sue is F, while if the speaker is Jane, what she said is that Jane is F. In uttering the very same sentence Sue and Jane express different propositions; one proposition has Sue as a constituent whereas the other proposition has Jane as a constituent. Sue intends to express a proposition about herself while Jane intends to express a proposition about herself. Since Sue and Jane utter an indexical sentence, though, they express a different proposition and they do

Manuscrito - Rev. Int. Fil., Campinas, v. 37 , n. 1, p. 5 - 50, jan.jun. 2014. 
so by uttering a sentence with the very same linguistic meaning (or same character, as Kaplan would put it). Moreover, their intention is explicitly articulated by their use of the first-person pronoun.

This is quite different from the case of a non-specific sentence, where we don't have indexicals (polysemy or ambiguity) at work. The proposition expressed (the official content) is thus the same. The propositions, though, are evaluated in the situations of their respective utterances. And if they are evaluated in different situations they can have different outputs as truth value.

It is noteworthy that the speakers' different intentions need not be resolved at the level of the reflexive content classifying their mental state. Instead, they can be resolved at the level of the official content by making reference to the situation of the utterance: namely, the situation in which the non-specific proposition that the A is not B is evaluated. Since, as I argued in the previous section, the speakers need not be aware of their intentions, it is not the job of semantics to spell them out. All we get from semantics, at the level of the official content, is a nonspecific proposition coupled with a situation we quantify over. This reflects the fact that agents can form goals and intentions at the subconscious level. The narrow/wide scope of 'not' need not be represented by a speaker of (1). For this reason, the reflexive content classifying the speaker's mental state (or thought) is silent concerning the scope of the negation.

The picture I have in mind rests on the distinction I mentioned in the previous section between context-sensitivity and situation-sensitivity. In short, the utterance of a non-eternal sentence is situation-sensitive insofar as its truth value depends on the situation in which it is evaluated. The latter, though, need not 
be represented by the speaker and/or hearer. On the other hand, the utterance of an indexical sentence is context-sensitive and the speaker needs to represent the referent(s) contextually singled out, i.e. needs to have the referent in mind. In other words, with an indexical sentence, the speaker entertains an indexical, de re, thought anchored to the relevant object indexically singled out. With an utterance of a non-indexical, yet situation-sensitive sentence, the speaker (and her audience) need not represent the relevant aspect of the situation when computing the utterance's truth value.

If a sentence contains, for instance, a meteorological verb like 'to rain' or 'to snow' the situational parameter relevant for the computation of the truth value of the utterance containing it is likely to be a location. With an utterance of "It's 3:15pm", it is likely to be a time zone, while with an utterance like "Haggis is tasty" or "Pop-art is interesting", it is likely to be a taste parameter, or standard of taste (cf. MacFarlane 2005, 2007). With 'not' the situational parameter should be the scope. A rational thinker, if questioned, after reflection, may resolve the scope of the negation. Yet, typical speakers may not be able to do so, for they may "unconsciously" think that the negation take narrow/predicate negation (or wide/sentence negation) scope. As communication is concerned, though, it can proceed successfully without the scope even having to be considered, let alone resolved. If it turns out that usual speakers tend to interpret the negation as having narrow scope, it would be akin to a presupposition that could be later denied or cancelled. To tell the same story in a different way, we could distinguish, following Bach, between a narrow and broad notion of context. While the former is (semantically) required to fix the value of indexical expressions (and as such operates by use of context at the semantic level), the latter helps in determining the

Manuscrito - Rev. Int. Fil., Campinas, v. 37 , n. 1, p. 5 - 50, jan.-jun. 2014. 
relevant parameters in the situation vis-à-vis which the proposition is evaluated (and as such operates by use of context at the postsemantic level). While the former is semantically mandated to fix the (propositional) content of an utterance containing indexicals, the latter is pragmatically required to determine the truth value of the proposition expressed by the given utterance. In terms of logical form we could say that with an indexical sentence we posit argument places for the indexical expressions, while with a non-indexical, yet situation sensitive sentence, all we need is to quantify over the situation with regard to which the proposition will be evaluated. The relevant situational parameters (what MacFarlane characterizes as nonstandard parameters) can be equated to pragmatic presuppositions. As I see them, these nonstandard parameters are not represented in the logical form of the sentence uttered; it is the utterance as a whole that pragmatically "indicates" the relevant parameters involved when evaluating the truth-condition of the proposition expressed, and it is for this very reason that the utterance exploits the broad context involved in the linguistic interchange. Among these parameters we may locate the speaker's intentions: in particular, the intentions guiding the speaker's communicative plan. In the case of the scope of the negation, it is likely that the (pragmatic) presupposition at work is that the negation takes narrow scope. If we ask someone, for instance, to "represent", say using an image, a sentence like "The king of France is not bald" they are likely to choose a picture (or draw one) with a hairy king. ${ }^{28}$ In other words, if we ask people to pair sentences of the form "The $F$ is not G" with pictorial representations the outcome to be expected is that our subjects would pair the relevant Fs lacking the G's properties and, thus, implicitly, considering the negation to take narrow scope. This

\footnotetext{
${ }^{28}$ Our subject is also operating with the presupposition that the description is not empty.

Manuscrito - Rev. Int. Fil., Campinas, v. 37 , n. 1, p. 5 - 50, jan.-jun. 2014.
} 
alleged exercise, though, happens at the postsemantic use of context; it enters the scene ad hoc, requiring the intervention of the reflexive mind. This seems to contrast with the resolution of other structural ambiguities that need to be solved at the pre-semantic use of context. If one is asked, for instance, to pair a sentence like "John saw Jane with the binoculars" (or "Flying airplanes can be dangerous") with pictorial representations, one ought to decide whether to choose a picture representing John with the binoculars close to his eyes or a picture showing Jane carrying binoculars. In such a case our subject will not "spontaneously" pair the sentence with one representation rather than the other. Our subject cannot appeal to default or presuppositions to solve the ambiguity, just as if one were asked to represent John going to the bank one ought to disambiguate the word 'bank' before choosing between the picture showing John dressed as a fisherman and the one showing John dressed in his suit.

Ultimately, these kinds of questions should be resolved by experimental inquiries: they cannot be dealt with by armchair philosophizing. That is, we cannot (or at least I'm unable to) propose an a priori argument suggesting that a typical speaker's default interpretation is the narrow (or wide) scope. All we can now say is that the scope problem in communication may be analogous to the example of the children with the time zone: their linguistic interaction can be successful without their having to articulate the time zone in their thought, let alone in the proposition expressed. The latter can rest "latent" or "dormant" in the relevant situation. The situational parameter relevant in determining the scope of 'not' in a sentence of the form "The A is not B" is the speaker's intentions as they may be manifested in her communicative plan. The latter, though, to borrow Baumeister's notion of the duplex mind (i.e. the distinction between the 
unconscious automatic system/mind and the conscious or reflective one), need not reach the reflective/conscious mind. The speaker's intention is likely to come to the surface only after reflection, possibly triggered by some misunderstanding or equivocation during the linguistic interchange. In short, the speaker and her audience can succeed in their linguistic interchange without having to entertain a specific thought (and the respective specific proposition) concerning the scope of the negation. The processing of a nonspecific thought and proposition may well suffice, with the scope ambiguity question never coming to the surface and the speaker and her audience never having to resolve it.

To summarize, the difference between a minimalist tenet that would accept Atlas' view that (1) is not ambiguous and the one that would appeal to the ambiguity thesis can be represented in adopting the T-schema. The minimalist who argues that (1) is structurally ambiguous would represent the truth-conditions of (1) as being either of the form:

(14) An utterance $u$ of "The $A$ is not $B$ " is true iff $\exists x[(A x$ $\& \forall y(\mathrm{Ay} \rightarrow \mathrm{x}=\mathrm{y})) \& \neg(\mathrm{Bx})]$

or

(15) An utterance $u$ of “The $\mathrm{A}$ is not $\mathrm{B}$ " is true iff $\neg \exists \mathrm{x}[(\mathrm{Ax}$ $\& \forall y(A y \rightarrow x=y)) \& B x]$

In this case, the ambiguity of (1) is resolved by use of context at the presemantic level, possibly appealing to the speaker's intention. In such a case, if John utters (1) intending the narrow scope readingthus expressing something whose truth-conditions would be captured by (14)-while Jane utters (1) intending the wide scope

Manuscrito - Rev. Int. Fil., Campinas, v. 37 , n. 1, p. 5 - 50, jan.-jun. 2014. 
reading-whose truth-conditions would be captured by (15)-we could not report that John and Jane said the same thing. However, this raises the following questions: How does an ordinary speaker form his/her intentions about the scope of the negation operator? These intentions, if they exist, are likely to operate at the subconscious level.

On the other hand, if one accepts the version of minimalism I've advocated, i.e. situated minimalism, we could classify John and Jane as being same-sayers for they both utter the same words and express the same nonspecific proposition..$^{29}$ In this case, the semantic content of both utterances can be captured by the truth-conditions in (13) where the relevant situation is quantified over. Under this version of minimalism, the ambiguity regarding the scope of the negation operator is not resolved at the presemantic level by use of context, but is instead resolved at the postsemantic one. Thus, pragmatic (and psycho-cognitive) considerations enter the scene only in order to determine the situation with respect to which the utterance must be evaluated. At the semantic level we can simply quantify over these situations.

\section{CONCLUSION}

Atlas' criticism may undermine Cappelen \& Lepore's version of minimalism for they assume, along the Fregean tradition, an absolutist notion of truth: viz., that a proposition (and, derivatively, the utterance expressing it) is true/false simpliciter and universally. If, instead, one assumes a form of situated minimalism where truth is relativized to situations, then Atlas' charge crumbles, for non-specificity-like other linguistic

${ }^{29}$ They wouldn't be same-sayers if we classify their utterance to be the Austinian proposition comprising the situation as well.

Manuscrito - Rev. Int. Fil., Campinas, v. 37 , n. 1, p. 5 - 50, jan.-jun. 2014. 
phenomena often mentioned by the friends of contextualism (who welcome pragmatic intrusions or contributions into what is literally expressed ${ }^{30}$ ) - can be dealt with by use of context at the postsemantic level. In short, the utterance of a non-specific sentence need not express-pace Atlas, minimalists like Cappelen \& Lepore, and the contextualists-a full-fledged proposition that is true/false simpliciter. It expresses a (minimal) proposition whose truth value depends on the situation vis-à-vis which it is evaluated. Pragmatic considerations may thus enter the scene when determining the situation in which the proposition is evaluated: they don't contribute, though, in the determination of the proposition expressed, i.e. what is strictly speaking said. As such, semantic non-specificity in no way threatens the version of situated minimalism I proposed.

\section{ACKNOWLEDGMENTS}

For comments and/or discussions on earlier version of this paper I would like to thank Jérôme Dokic, Kepa Korta, David Matheson, Stefano Predelli, Marco Ruffino and Ludovic Soutif. The comments of the referees have also been helpful. The research for this paper has been partially sponsored by a Social Sciences and Humanities Research Council of Canada grant, SSHRC (Standard Research Grant, 410-2010-1334), the Spanish Ministry of Science and Innovation (FFI2009-08574), and the Basque Government (IT323-10).

\footnotetext{
${ }^{30}$ See, for instance, the defenders of so-called truth-conditional pragmatics (e.g.: Bezuidenhout 2002, Carston 2002, and Recanati 2004). Manuscrito - Rev. Int. Fil., Campinas, v. 37 , n. 1, p. 5 - 50, jan.-jun. 2014.
} 


\section{REFERENCES}

ALMOG, J. \& PERRY, J. \& WETTSTEIN, H. Theme from Kaplan. Oxford University Press ,1989.

ATLAS, J.D. "Negation, Ambiguity, and Presupposition". Linguistics E Philosophy 1: pp. 321-36, 1977.

"Meanings, Propositions, Context, and Semantical Underdeterminacy”. In G. Preyer \& G. Peter (eds.). 2007. Context Sensitivity and Semantic Minimalism: New Essays on Semantics and Pragmatics. Oxford: Oxford University Press: pp. 217-39, 2007.

BACH, K. "Semantic Non-specificity and Mixed Quantifiers". Linguistics E Philosophy 4: pp. 593-605, 1982.

. "Conversational Implicitures". Mind and Language 9: pp. 124-62, 1994.

BARGH, G. \& CHARTRAND, T. "The Unbearable Automaticity of Being”. In D. L. Hamilton (ed.). Social Cognition: Key Readings in Social Psychology. New York: Psychology Press: pp. 228-48, 2005.

BARWISE, J. \& PERRY, J. Situations and Attitudes. Cambridge: MIT Press ,1983.

BARWISE, J. \& ETCHEMENDY, J. The Liar: An Essay on Truth and Circularity. Oxford: Oxford University Press, 1987.

Manuscrito - Rev. Int. Fil., Campinas, v. 37 , n. 1, p. 5 - 50, jan.-jun. 2014. 
BAUMEISTER, R. F. The Cultural Animal: Human Nature, Meaning, and Social Life. Oxford: Oxford University Press, 2005.

BEZUIDENHOUT, A. "Truth-Conditional Pragmatics". Philosophical Perspectives 16: pp. 105-34, 2002.

CAPELLEN, H. \& LEPORE, E. Insensitive Semantics. Oxford: Blackwell, 2005.

CARSTON, R. Thoughts and Utterances: The Pragmatics of Explicit Communication. Oxford: Blackwell, 2002.

CLARK, A. Microcognition: Philosophy, Cognitive Science and Parallel Distributed Processing. Cambridge: MIT Press, 1989.

. \& CHALMERS, D. "The Extended Mind". Analysis 58: pp. 10-23, 1998.

CORAZZA, E. "'She' and 'He': Politically Correct Pronouns". Philosophical Studies 111 (2): pp. 173-96, 2002.

. "Description-Names". Journal of Philosophical Logic 31 (4): pp. 313-25, 2002a.

. "Complex Demonstratives qua Singular Terms". Erkenntnis 59 (2): pp. 263-283, 2003.

. Reflecting the Mind: Indexicality and Quasi-Indexicality. Oxford: Oxford University Press, 2004.

Manuscrito - Rev. Int. Fil., Campinas, v. 37 , n. 1, p. 5 - 50, jan.jun. 2014. 
. "On Epithetsqua Attributive Anaphors". Journal of Linguistic 41 (1): pp. 1-34, 2005.

. "Contextualism, Minimalism, and Situationalism". Pragmatics and Cognition 15 (1): pp. 115-37, 2007.

. "Unenriched Sub sentential Illocutions". Philosophy and Phenomenological Research 83 (3): pp. 560-82, 2011.

. "Same-Saying, Pluri-Propositionalism, and Implicatures". Mind E Language27 (5): 546-69, 2012.

. \& KORTA, K. "Minimalism, Contextualism, and Contentualism". In P. Stalmaszczyk (ed.). Philosophy of Language and Linguistics (vol. 2): The Philosophical Turn. Frankfurt: Ontos-Verlag: pp. 9-39, 2010.

. \& DOKIC, J. "Situated Minimalism versus Free Enrichment”. Synthese 184 (2): pp. 179-98, 2012.

DAVIS, W. A. "Dyadic Contextualism and Content Relativism". Intercultural Pragmatics 10 (1): pp. 1-39, 2013.

DEVLIN, K. Logic and Information. Cambridge: Cambridge University Press, 1991.

KAPLAN, D. "Demonstratives". In J. Almog, J. Perry \& H. Wettstein (eds.) (1989). Themes from Kaplan. Oxford: Oxford University Press: pp. 481-563, 1977.

KORTA, K. \& PERRY, J. “Three Demonstrations and a Funeral”. Mind E Language 21 (2): pp. 166-86, 2006.

Manuscrito - Rev. Int. Fil., Campinas, v. 37 , n. 1, p. 5 - 50, jan.-jun. 2014. 
- ;

Critical Pragmatics: How We Say (and Mean)

Things with Words. New York: Cambridge University Press, 2011.

LEWIS, D. "Index, Content and Context". In S. Kanger and S. Ohman (eds.) Philosophy and Grammar. Dordrecht: Reidel: (1980), pp. 79-100. Reprinted in LEWIS, D. Papers in Philosophical Logic. Cambridge: Cambridge University Press: (1998), pp. 21-44.

MACFARLANE, J. "Future Contingents and Relative Truth". Philosophical Quarterly, 53: pp. 321-36, 2003.

- "Making Sense of Relative Truth". Proceedings of the Aristotelian Society 105: pp. 321-39, 2005.

. "Semantic Minimalism and Nonindexical Contextualism". In G. Prayer \& G. Peter (eds.) Context-Sensitivity and Semantic Minimalism. Oxford: Oxford University Press: (2007), pp. 240-50.

PERRY, J. “Thoughts without Representation". Proceeding of the Aristotelian Society 60: pp. 137-52. (1986). Reprinted in PERRY, J. The Problem of the Essential Indexical and Other Essays. Palo Alto CA: CSLI Publications: pp. 171-88. (2000).

PERRY, J. "Cognitive Significance and New Theories of Reference. Nous 22: pp. 1-18. (1988). Reprinted in PERRY, J. The Problem of the Essential Indexical and Other Essays. Palo Alto CA: CSLI Publications: pp. 189-206. (2000).

Manuscrito - Rev. Int. Fil., Campinas, v. 37 , n. 1, p. 5 - 50, jan.-jun. 2014. 
PERRY, J. Reference and Reflexivity: $2^{\text {nd }}$ Edition. Palo Alto: CSLI Publications. (2001/2012).

PREDELLI, S. Contexts. Oxford: Oxford University Press. (2005).

PRAYER G. \& PETER G. Context-Sensitivity and Semantic Minimalism. Oxford University Press, 2007.

RECANATI, F. Literal Meaning. Cambridge: Cambridge University Press, 2004.

ROBBINS P. \& AYDEDE M. The Cambridge Handbook of Situated Cognition. Cambridge: Cambridge University Press, 2009.

SNYDER, M., TANKE, E. D. \& BERCHEID, E. "Social Perception and Interpersonal Behavior: On the SelfFulfilling Nature of Social Stereotypes". Journal of Personality and Social Psychology 35: pp. 656-66, 1977.

SPERBER, D. \& WILSON, D. Relevance: Communication and Cognition. Oxford: Blackwell, 1986/95.

STANLEY, J. "Context and Logical Form". Linguistics $\mathcal{E}$ Philosophy 23: pp. 391-434, 2000.

STOKANOVIC, I. “The Problem of De Se Assertions". Erkenntnis 76 (1): pp. 49-58, 2011.

SUTTON, J. "Remembering”. In P. Robbins \& M. Aydede (eds.). The Cambridge Handbook of Situated Cognition. Cambridge: Cambridge University Press: (2009), pp. 217-235.

Manuscrito - Rev. Int. Fil., Campinas, v. 37 , n. 1, p. 5 - 50, jan.-jun. 2014. 
WILSON, R. \& CLARK, A. "How to Situate Cognition". In P. Robbins \& M. Aydede (eds.). The Cambridge Handbook of Situated Cognition. Cambridge: Cambridge University Press: (2009), pp. 55-77.

WILSON, D. \& SPERBER, D. "Truthfulness and Relevance". Mind 111 (443): pp. 583-632, 2002. 